\title{
Testing the performance of a prototype thermal energy storage tank working with organic phase change material for space heating application conditions
}

\author{
Maria K. Koukou, ${ }^{1, *}$, Michail Gr. Vrachopoulos ${ }^{1}$, George Dogkas ${ }^{1}$, Christos Pagkalos ${ }^{1}$, \\ Kostas Lymperis ${ }^{1}$, Luis Coelho ${ }^{2}$, and Amandio Rebola ${ }^{2}$ \\ ${ }^{1}$ National and Kapodistrian University of Athens, General Department, Energy and Environmental \\ Research Laboratory, 34400 Psachna Campus, Evia, Greece \\ ${ }^{2}$ Polytechnic Institute of Setubal, Portugal
}

\begin{abstract}
A prototype Latent Heat Thermal Energy Storage (LHTES) unit has been designed, constructed, and experimentally analysed for its thermal storage performance under different operational conditions considering heating application and exploiting solar and geothermal energy. The system consists of a rectangular tank filled with Phase Change Material (PCM) and a finned tube staggered Heat Exchanger (HE) while water is used as Heat Transfer Fluid (HTF). Different HTF inlet temperatures and flow rates were tested to find out their effects on LHTES performance. Thermal quantities such as HTF outlet temperature, heat transfer rate, stored energy, were evaluated as a function of the conditions studied. Two commercial organic PCMs were tested A44 and A46. Results indicate that A44 is more efficient during the charging period, taking into account the two energy sources, solar and heat pump. During the discharging process, it exhibits higher storage capacity than A46. Concluding, the developed methodology can be applied to study different PCMs and building applications.
\end{abstract}

\section{Introduction}

The building sector accounts for $40 \%$ of the total energy demand in the European Union [1, 2]. Thermal energy storage (TES) is among critical technologies for the exploitation of renewable energy for heating and cooling in buildings as it can store energy in peak supply and provide it in case of high demand reducing operating costs for the end users [3-5]. For the efficient operation of LHTES units it is important to select the PCM that should have desirable thermo-physical properties and design properly the unit. Two main categories of PCMs, organic, as paraffins, and inorganic, as salt hydrates, have been compared in review articles $[6,7]$. The first show better performance as salt hydrates face with drawbacks during phase change, such as supercooling and phase segregation impeding to take back thermal energy when the PCMs solidify. The melting point of some paraffins is suitable for building

\footnotetext{
*Corresponding author: mkoukou@uoa.gr, m_koukou@otenet.gr
} 
heating systems and they also show negligible corrosiveness to metals becoming more environmentally friendly than inorganic PCMs.

In a LHTES unit, a HE is used to transfer the thermal energy from a PCM to the HTF during charging and discharging [8]. The efficient design of HEs must take into account desired storage rate, transient PCM heat exchange and required energy storage capacity. It should also consider the PCM characteristics including low thermal conductivity, a major drawback of organic PCMs [9]. In order to overcome low conductivity, various engineering approaches have been suggested as the use of fins to maximize heat transfer as well as use of nanoparticles in the HTF [9].

Up to now, numerous experimental studies on the thermal performance of LHTES units have been conducted [8-14]. However, a limited number of the experimental studies have been reported that focus on building heating applications on a full scale [8]. Xu et al. [8] developed and tested a $0.38 \mathrm{~m}^{3}$ LHTES unit targeted integration with space heating systems for heating load management. They used cylindrically macro-encapsulated PCMs with a melting temperature range of $44-53{ }^{\circ} \mathrm{C}$ and with gross mass of $154 \mathrm{~kg}$. The unit has been tested with two tank orientations, horizontal and vertical and it was found that although the vertical orientation can shorten the charging/discharging time by up to $20 \%$ for the entire unit, it leads to decrease in PCM thermal capacity by at most $8.2 \%$. Hosseini et al. [10] examined the thermal performance of RT50, a commercial paraffin that completely melts above $51^{\circ} \mathrm{C}$ in a $1.0 \mathrm{~m}$ long finned cylinder with different fin heights and HTF inlet temperatures. Amini et al. [11] used embedded finned heat pipes in contact with a PCM in order to study the capability of such a LHTES system to store and release energy in a small volume compared to sensible heat TES system. Koukou et al [12] developed a LHTES small scale unit utilizing a compact fins and tube staggered HE and testing four organic PCMs with nominal melting temperatures between $40-53^{\circ} \mathrm{C}$. The experimental rig was also simulated by CFD and the results extracted were used to understand the process duration and the effect of the HTF flow rate along with the heat transfer mechanism acting in both melting and solidification processes considering the requirements for a heating application [15]. Gasia et al. [13] experimentally tested and compared in four LHTES systems the addition of fins and the use of two different HTFs based on the shell-and-tube heat exchanger concept, using paraffin RT58 as phase change material. Results indicate that finned designs show an improvement of up to $40 \%$. Medrano et al. [14] compared different types of heat exchangers operating with RT35 as PCM and water as HTF. Performance evaluation was based on the required time to fully melt a certain PCM quantity with different types of heat exchangers. Among them, the compact finned (staggered) heat exchanger made of aluminum fins and copper tubes widely used as evaporator or condenser in small air conditioning units, shows the highest ratio of heat transfer area to external volume. It has the highest average thermal power, with values above $1 \mathrm{~kW}$ for charging and discharging tests at cases with larger temperature differences between PCM and water.

This work focuses on the performance evaluation of a full scale PCM thermal energy storage unit under different operational conditions considering its coupling with building heating systems [15]. A LHTES tank with a compact finned HE immersed in PCM was designed and constructed. Two commercial organic PCMs, A44 and A46, are tested varying the inlet HTF temperature and flow rate. The performance of the tank using each PCM is analysed taking into account functionalities and responses during its use, both in the charging and the discharging process.

\section{HTES prototype and Experimental set-up}

The developed LHTES unit is a component of Tesse $2 b$ solution [15]. Tesse $2 b$ is a modular and low-cost thermal storage technology based on solar collectors and highly efficient heat 
pumps for heating, cooling and domestic hot water production. Its main components are the solar thermal collectors, the geothermal heat pump with vertical borehole HEs and the LHTES storage tanks with immersed HEs. In this work, results from the laboratory testing of the heating thermal energy storage tank (HTES) prototype are presented. As Tesse2b will be tested in three pilot sites in Europe [15] the conditions applied in the testing have been selected based on the characteristics of the sites. It is considered that the stored energy at temperatures between $38-45^{\circ} \mathrm{C}$ will be used for the TESSe $2 \mathrm{~b}$ heating system.

\subsection{LHTES prototype}

The tank was designed in a compact and modular manner considering usual container placement of stock building spaces for easy integration, insulation for minimum thermal losses according to existing standards [16]. The design allows flexible scaling of the system to meet thermal energy needs of residential buildings with various sizes and for different climates. The tank material is polypropylene which was preferred after extensive testing [17] and mainly due to better thermal properties specifications (long term working temperature approx. $90^{\circ} \mathrm{C}$ ). In order to suppress degradation due to contact with organic PCMs, the tank was epoxy coated as indicated by authors' previous studies [17]. The final design (Fig. 1) was concluded considering standard EN12573 [16] and FEA analysis. The tank is insulated with an $8 \mathrm{~cm}$ thick polyurethane layer and is enclosed in a thin steel shell while its upper surface can be accessed through an insulated lid. The nominal inner dimensions of the tank are length $1220 \mathrm{~mm}$, height $840 \mathrm{~mm}$ and width $300 \mathrm{~mm}$.
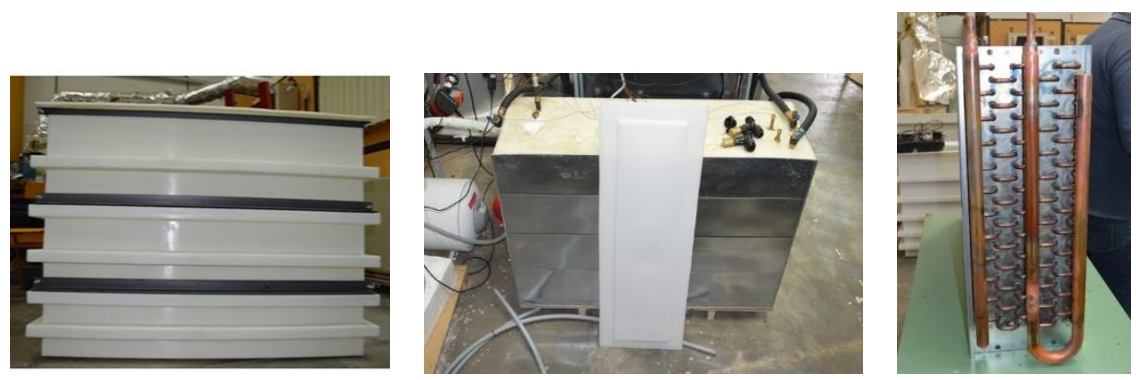

Fig. 1. (a) The HTES tank without and with insulation (b) View of the HE.

Regarding the HE type, it has been decided to work with a compact fins and tubes (staggered) heat exchanger (Fig. 1) made of aluminium fins and copper tubes that is widely used as evaporator or condenser in air conditioning units [14]. Experiments in small scale conducted prior to this work confirmed the adequacy of that HE type for the application considered [12]. The final HE design considers two circuits, each circuit has twelve parallel tubes and each one is $6 \mathrm{~m}$ long. One circuit is used to charge the tank by the solar collectors and the other is used for discharge the tank by the building heating system or to charge the tank by the heat pump system, making possible to charge the tanks by the solar collectors and discharge the storage energy for the building simultaneously. The HE was constructed by LUVATA-MODINE ${ }^{\circledR}$ based on 1022 commercial pattern. The inner and outer tube diameter was $7.75 \mathrm{~mm}$ and $9.525 \mathrm{~mm}$ respectively. The fin thickness was $0.3 \mathrm{~mm}$, the fin length $68 \mathrm{~mm}$ and fin spacing $5 \mathrm{~mm}$.

\subsection{PCMs tested}

The PCMs tested were selected considering that their melting/solidification temperature should match the heating application. Two commercial PCMs of PCM Products ${ }^{\circledR}$ [18] were 
selected, A44 and A46. A44 is a naturally derived blend of alkanes and A46 is a refined paraffin wax blend. The number next to "A" designates the nominal phase change temperature. Their thermophysical properties are shown in Table 1. A44 has a very narrow phase transition temperature range between $43-44^{\circ} \mathrm{C}$ while $\mathrm{A} 46$ has a wider phase transition temperature range between $46-48^{\circ} \mathrm{C}$.

Table 1. Thermal and physical properties of paraffin waxes according to the manufacturer [18].

\begin{tabular}{|c|c|c|}
\hline & $\mathbf{A 4 4}$ & $\mathbf{A 4 6}$ \\
\hline & 754 & 740 \\
\hline Density liquid $\left(\mathrm{kg} / \mathrm{m}^{3}\right)$ & 912 & 861 \\
\hline Density solid $\left(\mathrm{kg} / \mathrm{m}^{3}\right)$ & 0.24 & 0.24 \\
\hline Thermal conductivity liquid $(\mathrm{W} / \mathrm{m} \cdot \mathrm{K})$ & 0.24 & 0.24 \\
\hline Thermal conductivity solid $(\mathrm{W} / \mathrm{m} \cdot \mathrm{K})$ & 1800 & 1800 \\
\hline Specific heat liquid $(\mathrm{J} / \mathrm{kg} \cdot \mathrm{K})$ & 2400 & 2400 \\
\hline Specific heat solid $(\mathrm{J} / \mathrm{kg} \cdot \mathrm{K})$ & 268 & 126 \\
\hline Latent heat $(\mathrm{kJ} / \mathrm{kg})$ & &
\end{tabular}

\subsection{Experimental set-up}

The entire experimental rig is depicted in Fig. . Hot water was supplied by a 300 lt boiler with $12 \mathrm{KW}$ electric heaters and cold water was supplied by a 300 lt water buffer tank connected to an air-to-water chiller with $8.1 \mathrm{~kW}$ cooling capacity. Other equipment comprise two circulation pumps (Grundfos ${ }^{\circledR}$ ALPHA 2 32-60 180 inverter), two three-way temperature control valves (Belimo ${ }^{\circledR}$ LR24A-SR valve and Vector ${ }^{\circledR}$ TCI-W11 controller), two analog flowmeters (with measuring range of $4-100 \mathrm{lt} / \mathrm{min}$ ) with $\pm 5 \%$ accuracy, "T" type thermocouples with $+/-0.5^{\circ} \mathrm{C}$ accuracy and a data logger (National instrument ${ }^{\circledR} \mathrm{cDAq}-9174$ base, 2 x $921316 \mathrm{ch}$ cards, LabVIEW ${ }^{\circledR}$ data logger). Water is the selected HTF. To analyse HE thermal performance during the charging and discharging processes, temperature measurements are performed on HTF inlet and outlet temperature and also within the PCM volume. For the PCM temperature measurements, 27 thermocouples were positioned on a grid pattern covering the entire PCM volume.

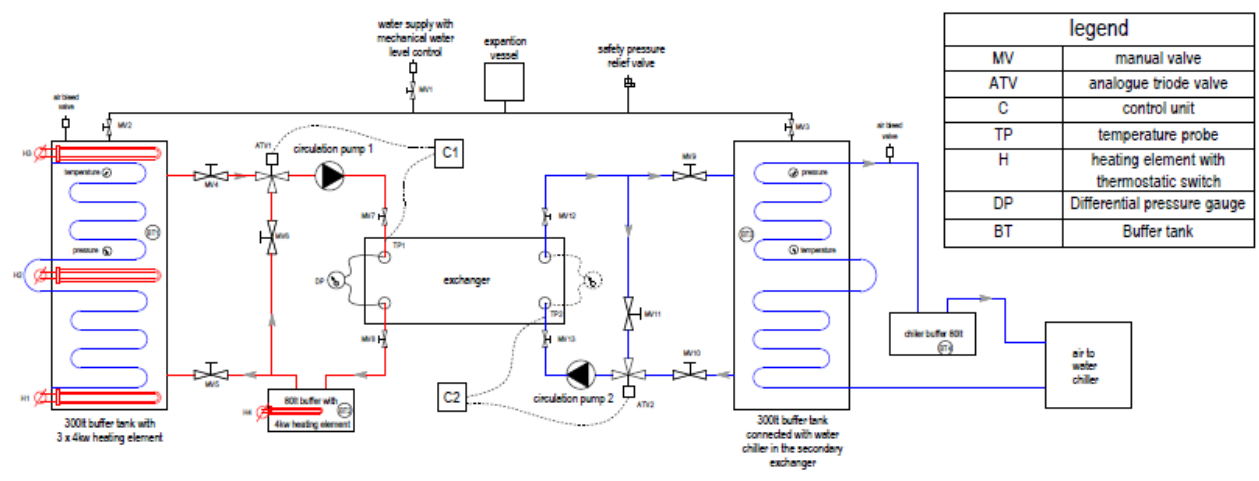

Fig. 2 Hydraulic scheme of the LHTES experimental rig.

\subsection{Experimental procedure and conditions}

The liquid PCM is put in the tank filling the space around the HE. Subsequently, it is left to cool up to room temperature with the tank lid open. Then, the hot water buffer supplies hot water and melts the PCM (Charging process). Just after the charging process, the hot water 
supply stops and cold water from the air-to-water chiller begins to circulate. The stored heat inside the PCM is now transferred to the cold water (Discharging process).

For each of the tested PCM, two sets of conditions were defined for tanks charging and discharging, taking into account the characteristics of the three pilot sites where the Tesse $2 \mathrm{~b}$ application will be tested at real conditions [15]. The set point discharge temperature considered, was $35^{\circ} \mathrm{C}$ because it is the expected return temperature of HTF in regular heating systems. The applied discharge flow rates were $20.4 \mathrm{l} / \mathrm{min}$ and $9.0 \mathrm{l} / \mathrm{min}$. The higher flow rate represents the most severe operating condition in the studied cases in Tesse $2 \mathrm{~b}$ pilot sites [15], this was made so that the tank discharge flow rate would match the water flow rate of the heat pump while operating in heating mode. The lower flow rate represents the same heating mode but with the lower nominal flow rate of the heat pumps, such as it happens in one of the Tesse $2 \mathrm{~b}$ demo sites [15]. The charging temperature was selected between 50 and $53.5^{\circ} \mathrm{C}$, these temperatures are in the range of what is expected to be met in real operation, with two selected flow rates: $17.7 \mathrm{l} / \mathrm{min}$ and $9 \mathrm{l} / \mathrm{min}$. The high flow rate was selected based on the estimated nominal water flow rate of the solar collectors, with all collectors working to charge directly a single PCM tank at a time. The low flow rate was estimated based on the heat pump in one of the demo sites working in nominal conditions and considering the number of HTES tanks in that site [15].

\section{Typical results and discussion}

In the literature there is no common and widespread procedure for evaluating latent heat storage performance $[4,5]$. For that reason, it was decided to analyze the performance of the storage tank taking into account its functionalities and responses during its use, both in the charging process and in the discharging process. Important parameters are the total stored energy, for an effective use, which depends not only on the whole tank characteristics, including the HE and PCM, but also on the heating system characteristics. Stored energy is the energy that water delivers/absorbs to/from the system. Other important parameter is the heat transfer rate and its temporal evolution and for different amount of the stored energy available at each instant. The water temperature at the outlet of the tanks or the delta $\mathrm{T}$ between the inlet and the outlet are also critical parameters. To heat the house the hot water will be dissipated by terminal units e.g. fan-coil units (FCUs) or heating floor. The performance of those units depends of the indoor air and the temperature of the water received by the units. Therefore, it is important to know the water temperature at the outlet of the tanks along the time and for different amount of energy stored, to know if it is possible to use the temperature in the terminal units directly from the tanks or it is necessary to have some support of the heat pump to give an increase in temperature (preheating).

In Fig. 3 the outlet water temperature as a function of the stored energy is presented for two different flow levels $(20.4 \mathrm{l} / \mathrm{min}$ and $9 \mathrm{l} / \mathrm{min})$. The dotted line is the temperature of the water at the tank inlet or the return from the FCUs. The tank outlet is not allowed to fall below $35^{\circ} \mathrm{C}$ and thus the tank is considered empty when the delta $\mathrm{T}$ is almost zero. As the water flow increases the temperature difference between water inlet and outlet decreases for both PCM types. This is normal behaviour if the load - efficiency curve of a heat exchanger is considered. The storage capacity of the tank decreases as the discharge rate increases and this is also due to the HE efficiency and the nature of the PCM materials which have relatively high thermal resistance. A44 shows greater storage capacity up to $9.5 \mathrm{kWh}$ per tank while the A46 can only store up to $4.7 \mathrm{kWh}$ per tank. A46 has higher delta T between inlet and outlet which positively affects the performance of the FCUs.

In Fig. 4 the temperature difference between water inlet and outlet of the tank (Delta T) as a function of the stored energy percentage is presented. Delta $\mathrm{T}$ is important for the 
building heating system functionality because the nominal FCU output power is derived by the standard using $5^{\circ} \mathrm{C}$ Delta $\mathrm{T}$.

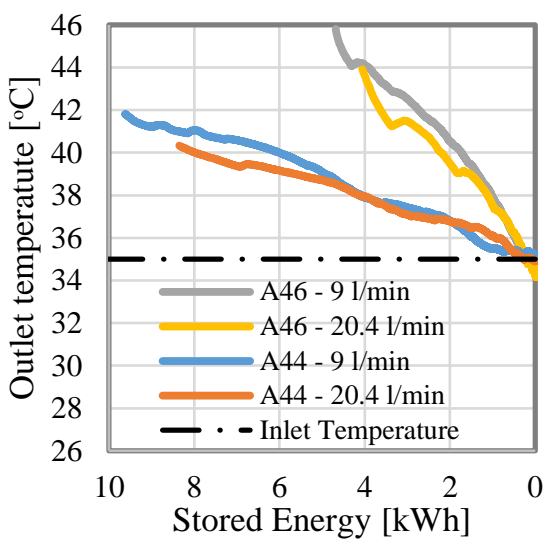

Fig. 3. Water outlet temperature temporal evolution as a function of stored energy.

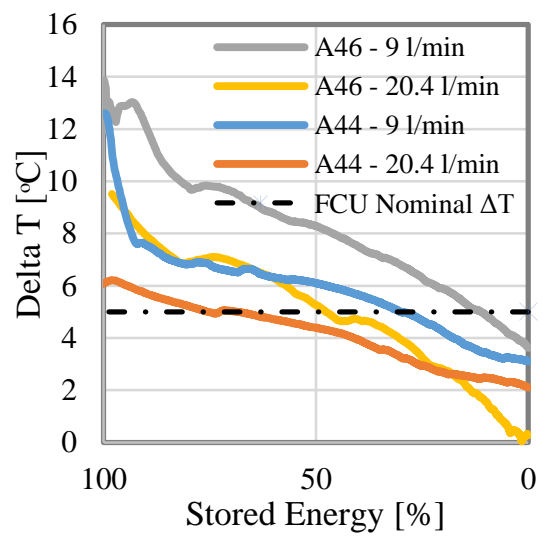

Fig. 4. Delta $T$ as a function of stored energy percentage.

If the water temperature difference between the inlet and outlet of the FCU changes so does its output power. For that purpose, the dotted line shows how much each tank can be discharged before Delta $\mathrm{T}$ falls below $5^{\circ} \mathrm{C}$ to assure the desired performance from the FCUs. A46 initially shows superior performance. The A46 tank can be discharged down to $26 \%$ or 9\% depending on the water flow volume. The A44 can be discharged down to $63 \%$ or $46 \%$ respectively. Thus, the usable power for both tanks can be derived by:

$$
\begin{gathered}
P_{A 46}=(100 \%-9 \%) \cdot Q_{\max A 46}=0.91 \cdot 4.7 \mathrm{kWh}=4.28 \mathrm{kWh} \\
P_{A 44}=(100 \%-46 \%) \cdot Q_{\max A 44}=0.54 \cdot 9.5 \mathrm{kWh}=5.13 \mathrm{kWh}
\end{gathered}
$$

It is clearly observed that even when the A44 tank is discharged only to $46 \%$, it can give more energy than the A46 discharged down to $9 \%$.

Fig. 5 shows the output heat transfer rate against the stored energy inside the tank. A46 tank shows superior performance as it can provide high output heat rate if needed.

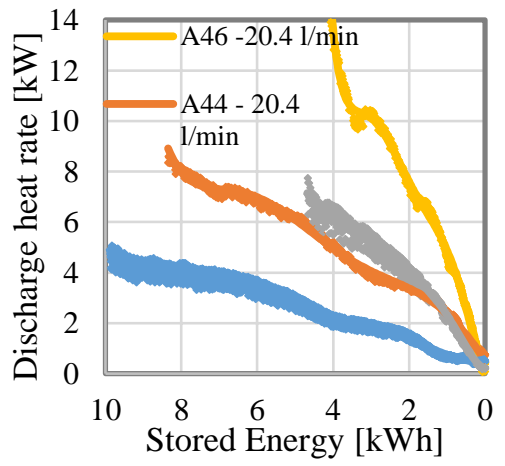

Fig. 5. Discharged heat rate as a function of stored energy.

With the high flow rate of $20.4 \mathrm{l} / \mathrm{min}$ it can give out up to $14 \mathrm{~kW}$. A44 tank still maintains fare output heat rate up to $8.3 \mathrm{~kW}$ for the high flow rate, however, it has the advantage of higher storage capacity. In Figs. 6, 7 results from the charging tanks performance are shown. 
The tank must be able to charge by both solar collectors and geothermal heat pump to achieve seamless system integration and thus energy savings. The flow rates for the charging evaluation is derived by selected solar collector and heat pump characteristics that match the need of the pilot sites where the tanks are installed [15]. For charging the tanks, different water inlet temperatures are used for each PCM, shown with the dotted lines. The inlet temperature for $\mathrm{A} 44$ is $50^{\circ} \mathrm{C}$ and for the $\mathrm{A} 46$ is $52^{\circ} \mathrm{C}$. A44 tank keeps relatively constant output temperature over the charging cycle. In the range of $2 \mathrm{kWh}$ to $10 \mathrm{kWh}$, the temperature is relatively constant and about the same for both charging rates. This increases the efficiency of the entire heating system and helps the installers with the sizing of the rest of the system parts (namely: heat - pump, FCUs and solar collectors). The corresponding for the discharging phase, the stored energy efficiency of the tanks can be derived:

$$
\begin{gathered}
n_{\text {A44 high flow }}=\frac{Q_{\max A 44 \text { (discharging high flow) }}}{Q_{\max A 44 \text { (charging high flow) }}}=\frac{8.29 \mathrm{kWh}}{9.15 \mathrm{kWh}}=90.6 \% \\
n_{\text {A44 low flow }}=\frac{Q_{\max A 44 \text { (discharging low flow) }}}{Q_{\max A 44 \text { (charging low flow) }}}=\frac{9.54 \mathrm{kWh}}{10 \mathrm{kWh}}=95.4 \% \\
n_{\text {A46 high flow }}=\frac{Q_{\max A 46 \text { (discharging high flow) }}}{Q_{\max A 6 \text { (charging high flow) }}}=\frac{4.04 \mathrm{kWh}}{5.39 \mathrm{kWh}}=75 \% \\
n_{\text {A46 low flow }}=\frac{Q_{\max A 46(\text { discharging low flow) }}}{Q_{\max A 6 \text { (charging low flow) }}}=\frac{4.65 \mathrm{kWh}}{5.09 \mathrm{kWh}}=91.3 \%
\end{gathered}
$$

A44 shows better efficiency for both flow rates. Finally, in Fig. 7, the heat transfer rate for the charging phase. In this it can be seen that A44 tank maintains higher heat transfer rate over almost the entire charging phase and thus enables better integration of the charging devices (namely solar collectors and heat pumps).

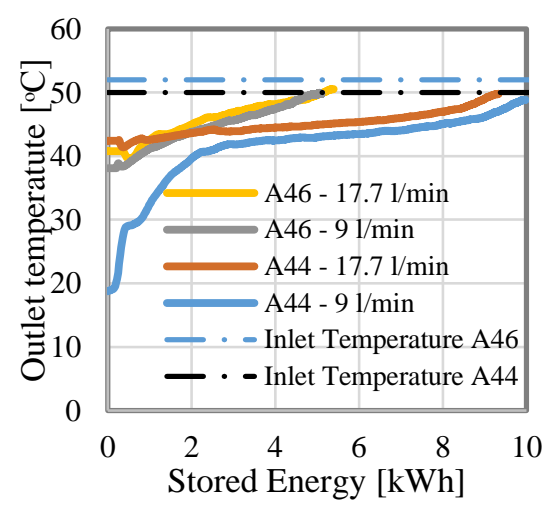

Fig. 6. Water outlet temperature as a function of stored energy.

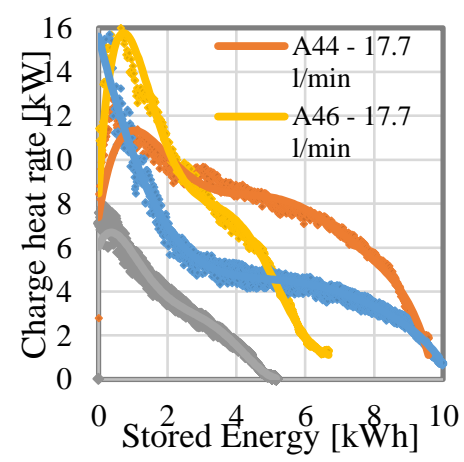

Fig. 7. Charged heat rate as a function of stored energy.

\section{Conclusions}

A full scale PCM HTES prototype has been designed, constructed and tested under different operational conditions considering its coupling with building heating systems [15]. Two commercial organic PCMs, A44 and A46, are tested with varying the inlet HTF temperature 
and flow rate. A44 has higher volumetric capacity than A46 and narrow phase transition temperature range. Based on testing results, it was found that A44 exhibits higher storage capacity than A46 during charging taking into account the two sources of energy, solar and heat pump. It also exhibits faster heat transfer rate and provides more constant water outlet temperature than A46 during charging. During the discharging process, taking into account the typical characteristics of terminal units it is proved that A44 is possible to use all latent heat energy, and under certain conditions it may be necessary to have the heat pump support. It also exhibits higher storage capacity than A46 during discharging. Concluding, A44 outperforms A46 and it can be proposed for use in the heating application.

The work is supported by TESSe2b project which has received funding from the European Union's Horizon 2020 research and innovation program under grant agreement No 680555.

\section{References}

1. J. Lizana, R. Chargartegui, A. Barrios-Padura, C. Ortiz, Renew. Sustain. Energy Rev. 82, 3705 (2018)

2. EU Directive on the Energy Performance of Buildings (recast) (2010/31/EU)

3. J. Heier, C. Bales, V. Martin, Renew. Sustain. Energy Rev. 42, 1305 (2015)

4. V. Palomba, A. Frazzica, Energy Build. 185, 88 (2019)

5. J. Romani, J. Gasia, Ar. Sole, H. Takasu, Y. Kato, L. F. Cabeza, Applied Energy 235, 954 (2019)

6. L. F. Cabeza, A. Castell, C. Barreneche, A. de Gracia, A.I. Fernández, Renew. Sustain. Energy Rev. 15, 1675 (2011)

7. C. N. Elias, V. N. Stathopoulos, Energy Procedia, in press (2019)

8. T. Xu, J. Ningwei Chiu, B. Palm, S. Sawalha, Energy Conversion and Management 182, 166, 166-177 (2019)

9. L. Liu, D. Su, Y. Tang, G. Fang, Sustainable Energy Rev. 62, 305 (2016)

10. M. J. Hosseini, A. A. Ranjbar, M. Rahimi, R. Bahrampoury, Energy Build. 99, 263 (2015)

11. A. Amini, J. Miller, H. Jouhara, Energy 136, 163 (2017)

12. M. K. Koukou, M. Gr. Vrachopoulos, N. S. Tachos, G. Dogkas, K. Lymperis, V. Stathopoulos, Thermal Science and Engineering Progress 7, 87 (2018)

13. J. Gasia, J. Diriken, M. Bourke, J. Van Bael, L. F. Cabeza, Renewable Energy 114, 934 (2017)

14. M. Medrano, M. Yilmaz, M. Nogues, I. Martorell, J. Roca, L. F. Cabeza, Applied Energy 86, 2047 (2009)

15. Tesse $2 \mathrm{~b}$ project deliverable 8.5: Training material, [Online]. Available:

http://www.tesse2b.eu/Content/images/tesse2b/Training_Material.pdf. [Accessed February 2019]

16. BS EN 12573-3: 2000 Welded static non-pressurised thermoplastic tanks. Part 3

17. V. Chalkia, N. Tachos, P. K. Pandis, A. Giannakas, M. K. Koukou, M. Gr. Vrachopoulos, L. Coelho, A. Ladavos, V. N. Stathopoulos, RSC Adv. 8, 27438 (2018)

18. http://www.pcmproducts.net/," PCM Products Ltd., [Online]. Available: http://www.pcmproducts.net/. [Accessed February 2019] 